\title{
STUDENTS' PERCEPTIONS OF E LEARNING IN TEACHER EDUCATION UNIVERSITY IN VIET NAM
}

\author{
DR. LAN CHI LE ${ }^{1}$, DR. THAI DINH DO ${ }^{2} \&$ ANH-MINH TRAN-QUANG \\ ${ }^{1}$ Vice Rector, Saigon University, Vietnam \\ ${ }^{2}$ Lecturer, Saigon University, Vietnam \\ ${ }^{3}$ Ho Chi Minh City University of Education, Vietnam
}

\begin{abstract}
The findings of this study, a cross-sectional exploratory survey, which was conducted in Ho Chi Minh City's universities, has assessed the Vietnamese undergraduates' E-learning system quality. It was hypothesized that students hold a positive attitude towards different aspects of E-learning system quality. Nine hundred fourteen students, including 352 males and 562 females, participated and used the E-learning System Quality Scale. Data were then gathered by the Vietnamese Education Management, Psychology undergraduates during their school-time. Descriptive and inferential statistics were used to analyze the data. Cochrane methodology was applied to determine the sample size, and the MANOVA test was used to assess differences between each group. The results found that in regard to the E-learning system quality scores, males were found to have higher scores than females. Males held higher scores than females when considering Elearning instructor and course materials quality (EICMQ), E-learning administrative, and support service quality (EASSQ). Moreover, the scores of seniors were found to be higher than those of the freshman, sophomores, and juniors on the E-learning service quality attribute (ESQA), E-learning instructor, and course materials quality (EICMQ) scores. The students who had gone under the study showed a positive attitude to E-learning, and they would be interested in performing E-learning.

KEYWORDS: E-Learning, University, Student
\end{abstract}

Received: Jun 06, 2020; Accepted: Jun 26, 2020; Published: Aug 31, 2020; Paper Id.: IJMPERDJUN2020974

\section{INTRODUCTION}

The growth of education faces a constant evolution, and the adoption of new technologies for education is reflected in the inclusion of virtual courses in the educational process as well as the growth of E-learning (Amado-Salvatierra et al., 2016; Tsai \& Hsu, 2010). E-learning technologies offer learners to control over the content, learning sequence, the pace of learning, time, and often media, allowing them to tailor their experiences to meet their learning objectives (Trukhacheva et al., 2011)

E-learning was an instructional strategy for imparting needed knowledge, skills, experience, instructor methods, instructor preparation, and the sense of teaching/learning (Azeiteiro et al., 2015; Garavan et al., 2010). According to research by (Mayer \& Moreno, 2010), the E-learning system brings many benefits in enhancing knowledge and performance, skills, and attitudes (Garavan et al., 2010; McKenzie \& Murray, 2010) and reducing learning costs (Harris et al., 2011; Mayer \& Moreno, 2010; Zhang \& Nunamaker, 2003). Besides, learning has grown from the new learning requirements that are dynamically changing (Judy et al., 2012). Learning/teaching tool 
is also expanding now (Borgman, 2010; Haines, 2016). In general, the E-learning course was rated positively concerning learning as well as preparation for the national training course (Fagö-Olsen et al., 2020). According to González-Gómez et al. (2012) and Zakarneh (2018) they showed that female students are more pleased with the subjects of E-learning than male students. Besides, female students put greater emphasis on learning preparation, as well as being able to reach the instructor in several ways. Another study of Liaw and Huang (2011) indicated that male students have a more optimistic Elearning mindset than female students do.

Moreover, seniors' scores were found higher than those of the Freshman, Sophomore, and Juniors on the Elearning system quality scores. However, Hung et al. (2010) the study showed that no statistical differences were revealed in gender among the five Online Learning Readiness Scale dimensions, including self-directed learning, online communication self-efficacy, motivation for learning, and learner control. Meanwhile, junior and senior students demonstrated substantially greater preparation in the dimensions than freshman and sophomore students. Research by Tee and Lee (2011) they found that both E-learning groups improved more than the traditional groups. Improvement scores were four for CF; 8.6 for PPT and 2.8 for SW. Research by Ludwig et al. (2016) also revealed that the students, as well as the academic staff, have an excellent positive attitude toward applying E-learning. Similarly, results in research of Pham et al. (2019) show that the overall E-learning service quality was positively related to E-learning student satisfaction, which in turn positively influences E-learning student loyalty.Edwards and Bone (2012) findings indicated that interfacing Peer Assisted Learning and eLearning provided an essential context for re-positioning the ways in which tutorials and lectures could be used as a basis for collaborative learning between students and lecturers alike (Freeze et al., 2019). According to Cole et al. (2014) found that students rated their online instruction as moderately satisfactory. However, they are not mentioned about undergraduates' perception of Elearning. While several such studies have been conducted for different nations, no research has yet examined the perception of E-learning in teacher Education in Vietnam. The purpose of this study was to investigate the level of Elearning, essential needs during university education, and relationships between quality E-learning of university students. A simple analytical framework is introduced in the second section, followed by research methodology, results, and discussion. The last section is the conclusion.

\section{The Following Null Hypotheses were Tested}

\section{Hypotheses}

A $4 \times 2$ factorial design was used. The independent variables were two students' characteristics: school years (freshman, sophomore, junior, senior), and gender (male and female). Three dependent variables were measured: E-learning service quality attribute (ESQA), E-learning instructor, and course materials quality (EICMQ), E-learning administrative and support service quality (EASSQ). The following null hypotheses were tested:

$\mathbf{H}_{\mathbf{0 1}}$ (main effect): There are no significant differences between male and female groups of students when they are compared simultaneously on the E-learning service quality attribute (ESQA), E-learning instructor, and course materials quality (EICMQ), E-learning administrative and support service quality (EASSQ).

$\mathbf{H}_{\mathbf{0} 2}$ (main effect): There are no significant differences between freshman, sophomore, junior, and senior groups of students when they are compared simultaneously on the E-learning service quality attribute (ESQA), E-learning instructor and course materials quality (EICMQ), E-learning administrative and support service quality (EASSQ). 
$\mathbf{H}_{\mathbf{0 3}}$ (interaction effect): There are no significant interactions between the school year and gender groups of students when they are compared simultaneously on the E-learning service quality attribute (ESQA), E-learning instructor, and course materials quality (EICMQ), E-learning administrative and support service quality (EASSQ).

\section{METHODOLOGY}

\section{Data Collection}

The research participants were 914 Vietnamese of twoTeacher Education Universities in Ho Chi Minh City, Vietnam. The survey instrument was distributed to 950 Vietnamese students of two Universities located in Ho Chi Minh City, Vietnam, of which 914 questionnaires were returned, with a return rate of 80 percent, which had exceeded the 30 percent response rate most researchers require for analysis(Dillman, 2000; Le \& Tran-Chi, 2019). The sample of this study was drawn from 914 respondents who completed the survey instrument, including 352 males (149 freshmen, 116 sophomores, 56 juniors, 31 seniors) and 562 females (191 freshmen, 194 sophomores, 137 juniors, 40 senior). The researchers had contacted the individual faculty of each University prior to questionnaire distribution. The researchers contacted the representatives of two universities' including the Ho Chi Minh City University of Education, Saigon University, with their consent, explained the purpose of the study before delivering questionnaires. Only if all participants were voluntarily willing to complete the questionnaires, the research was conducted. There were more females $562(61.5 \%)$ than males $352(38.5 \%)$ among the 914 students who were surveyed, including 340 freshmen, 310 sophomores, 193 juniors, and 71 seniors. Table 1 shows the distribution of participants in the School year by Gender groups.

Table 1: Number of Participants in the School Year by Gender Groups

\begin{tabular}{|l|c|c|c|}
\hline \multirow{2}{*}{\multicolumn{1}{|c|}{ School Year }} & \multicolumn{3}{c|}{ Gender Group } \\
\cline { 2 - 4 } & Male & Female & Total \\
\hline Freshman & 149 & 191 & 340 \\
\hline Sophomore & 116 & 194 & 310 \\
\hline Junior & 56 & 137 & 193 \\
\hline Senior & 31 & 40 & 71 \\
\hline
\end{tabular}

\section{Measurement}

Participants were asked to complete the following questionnaire: the Vietnamese versions of the E-learning system quality scale (ESQS) for students based on the original Pham et al. (2019). The ESQS consists of three subscales: E-learning service quality attribute (ESQA), E-learning instructor, and course materials quality (EICMQ), E-learning administrative and support service quality (EASSQ). The 31 items of ESQS were translated into Vietnamese by two bilingual researchers who were both familiar with the construct being assessed. For one of them, the first language was Vietnamese, and the other the first language was English. Forward and backward translation procedures were used. The same sequence of items was maintained in the Vietnamese translation of the index. All participants were instructed to read the questionnaire questions carefully and choose the responses that best described themselves. The ESQS consists of 31 items measured on a 5-point Likert scale in which the 1 indicates a response of 'strongly disagree,' while the value of 5 corresponds to 'totally agree.' The internal consistency reliability (Cronbach's alpha) estimate for this sample was reasonably high at .60 (Bowling, 2014). Alpha coefficients for each subscale were as follows: E-learning service quality attribute (ESQA):0.97 Elearning instructor and course materials quality (ESQA): 0.96, E-learning administrative and support service quality (EASSQ):0.94 (Pham et al., 2019). One possible reason for the higher reliability of the subscale of the ESQS scale could be the contextual differences; students responded to scale items according to their own understanding level.E- 
learningSystem Quality Scale (ESQS). The mean score for the sample on the ESQS (total score) was 88.56 ( $\mathrm{SD}=26.43$ ). The mean score on the ESQA subscale was $34.02(\mathrm{SD}=10.15)$. The mean score on the EICMQ subscale was $36.17(\mathrm{SD}=$ 11.03). The mean score on the EASSQ subscale was18.37(SD =6.82). Table 2 presents descriptive statistics of dependent variables, including ESQA, ESQA, and EASSQ results by School year and Gender groups.

\section{RESULTS AND DISCUSSION}

\section{Data Analysis}

Descriptive and inferential statistics (Cohen, 2013) were performed using the Statistical Package for the Social Sciences (SPSS) version 20.0. Descriptive statistics were used to analyze the data collected. A two-way MANOVA was performed with two independent variables (school year and gender) and subscales of the ESQS as dependent variables. The average item means average standard deviation, F values, and effect sizes from MANOVA were calculated for each of the scales of the ESQS. These analyses were used to investigate differences in the E-learning service quality attribute (ESQA), Elearning instructor and course materials quality (ESQA), E-learning administrative and support service quality (EASSQ) to the of Vietnamese students' base on the school year and gender.

Table 2: Number of Participants in Grade by Gender Groups

\begin{tabular}{|l|c|c|c|c|c|}
\hline \multirow{2}{*}{ Gender } & \multicolumn{5}{|c|}{ School Year Group } \\
\cline { 2 - 6 } Male & Freshman & Sophomore & Junior & Senior & Combined \\
\hline ESQA & & 116 & 56 & 31 & 352 \\
\hline M & 32.98 & 33.27 & 32.03 & 34.52 & 33.06 \\
\hline SD & 10.82 & 9.98 & 8.62 & 11.41 & 10.25 \\
\hline EICMQ & & & & & \\
\hline M & 34.70 & 35.93 & 33.00 & 36.00 & 34.95 \\
\hline SD & 11.33 & 10.84 & 10.18 & 13.26 & 11.18 \\
\hline EASSQ & & & & & \\
\hline M & 17.21 & 18.23 & 16.60 & 19.29 & 17.64 \\
\hline SD & 7.13 & 6.40 & 6.23 & 8.06 & 6.87 \\
\hline Female & 191 & 194 & 137 & 40 & 562 \\
\hline ESQA & & & & & \\
\hline M & 33.03 & 36.08 & 34.26 & 36.25 & 34.62 \\
\hline SD & 9.98 & 9.68 & 10.09 & 10.92 & 10.04 \\
\hline EICMQ & & & & & \\
\hline M & 17.21 & 18.26 & 16.61 & 19.29 & 17.64 \\
\hline SD & 7.13 & 6.40 & 6.30 & 8.06 & 6.87 \\
\hline EASSQ & & & & & \\
\hline M & 17.76 & 19.75 & 18.86 & 19.25 & 18.83 \\
\hline SD & 6.63 & 6.45 & 7.15 & 6.95 & 6.76 \\
\hline
\end{tabular}

\section{Inferential Analysis}

The null hypotheses were tested using a two-way multivariate analysis of variance (MANOVA). Using MANOVA, the multiple dependent variables should be related to each other at a low to a moderate level (Pallant, 2016). More specifically, a high correlation (.50 to 1 ) among dependent variables shows multicollinearity and small to medium correlation ( \pm .10 to \pm .49) among dependent variables show singularity. Table 3 revealed that all values were more than .86 , which provides controlling singularity assumption. Besides, Pallant (2016) stated that correlations around .80 or .90 cause violation of multicollinearity assumption. Since all values were under .90 multicollinearity, the assumption was also checked. 
Table 3: Correlations Matrix

\begin{tabular}{|c|c|c|c|}
\hline & ESQA & EICMQ & EASSQ \\
\hline ESQA & 1 & $.82^{* *}$ & $.81^{* *}$ \\
\hline EICMQ & & 1 & $.86^{* *}$ \\
\hline EASSQ & & & 1 \\
\hline
\end{tabular}

**. Correlation is significant at the 0.01 level (2-tailed).

The researchers tested all the assumptions, and the results were positive except the Box's test of equality of variance. MANOVA is robust to violations of homogeneity of variance-covariance matrices if the sizes of groups are nearly equal or if the size of the largest group is less than about 1.5 times the size of the smallest group (Leech et al., 2005). Although the largest group in this research $(n=194)$ was about 6.3times larger than the smallest group $(n=31)$, the multivariate homogeneity of covariance matrices tested with Box's $M$ test revealed that the $M$ value of 52.72 was not significant $(\mathrm{p}=.18)$. Therefore, the assumption of homogeneity of covariance matrices was satisfied.

The MANOVA revealed a significant multivariate effect for theschool year, Wilks' Lambda $=.98, F_{(9,2200)}=2.1, p$ $<.026$, partial $\eta 2=.007$, and a non-significant multivariate effect for gender, Wilk's Lambda $=.99, \mathrm{~F}_{(3,904)}=1.6, \mathrm{p}>.18$, partial $\eta 2=.005$. A non-significant multivariate effect for interaction was also found, Wilk's Lambda $=.99, \mathrm{~F}_{(9,2200)}=.85, \mathrm{p}$ $>.56$, partial $\eta 2=.003$. Therefore, the results suggested that the first hypothesis $\left(\mathrm{Ho}_{1}\right)$ was rejected, but the second hypothesis $\left(\mathrm{Ho}_{2}\right)$ and third hypothesis $\left(\mathrm{Ho}_{3}\right)$ were not rejected.

Based on the significant effects found from the MANOVA, a separate two-way univariate analysis of variance (ANOVA) for each of the dependent variables was conducted without undue inflation of the experiment wise Type I error (Grimm \& Yarnold, 1995). The Levene's test revealed that the assumption of homogeneity of variances was met for ESQA $[\mathrm{F}(7,906)=.55, \mathrm{p}>.79], \operatorname{EICMQ}\left[\mathrm{F}_{(7,906)}=.92, \mathrm{p}>.49\right], \operatorname{EASSQ}\left[\mathrm{F}_{(7,906)}=.79, \mathrm{p}>.59\right]$.

The ANOVA results as shown in Table 4 revealed the interaction effect was non-significant $(\mathrm{p}>.05)$. A significant school year effects on ESQA $\left[F_{(3,906)}=2.22, M S E=104.91, p<.08\right.$, Partial $\left.\eta 2=.007\right]$, EICMQ $\left[F_{(3,906)}=3.15\right.$, $M S E=120.11, p<.02$, Partial $\eta 2=.007]$, EASSQ $\left[F_{(3,906)}=3.43, M S E=45.92, p<.02\right.$, Partial $\left.\eta 2=.011\right]$ among the Freshman, Sophomore, Junior and Senior (Freshman: $\mathrm{M}_{\mathrm{ESQA}}=33.01, \mathrm{M}_{\mathrm{EICMQ}}=35.15, \quad \mathrm{M}_{\mathrm{EASSQ}} \quad=17.50$, $\mathrm{M}$ total $=28.55$; Sophomore: $\mathrm{M}_{\mathrm{ESQA}}=34.68, \mathrm{M}_{\mathrm{EICMQ}}=37.39, \mathrm{M}_{\mathrm{EASSQ}}=19.01, \mathrm{M}_{\text {total }}=30.36$; Junior: $\mathrm{M}_{\mathrm{ESQA}}=33.15, \mathrm{M}_{\mathrm{EICMQ}}=34.56$, $\mathrm{M}_{\mathrm{EASSQ}}=17.74, \mathrm{M}_{\text {total }}=28.48$; Senior: $\mathrm{M}_{\mathrm{ESQA}}=35.38, \mathrm{M}_{\mathrm{EICMQ}}=36.40, \mathrm{M}_{\mathrm{EASSQ}}=19.27, \mathrm{M}_{\text {total }}=30.35$ ). Significant gender effects on ESQA $[\mathrm{F}(1,906)=4.22, M S E=101.91, p<.040$, Partial $\eta 2=.005]$, EICMQ $[\mathrm{F}(1,906)=4.60, M S E=120.10, p<$ .032 , Partial $\eta 2=.005]$, EASSQ $[F(1,906)=3.70, M S E=45.92, p<.055$, Partial $\eta 2=.004]$ among males and females (Male: $\mathrm{M}_{\mathrm{ESQA}}=33.20, \mathrm{M}_{\mathrm{EICMQ}}=34.91, \mathrm{M}_{\mathrm{EASSQ}}=17.84, \mathrm{M}_{\text {total }}=28.65 ;$ Female: $\mathrm{M}_{\mathrm{ESQA}}=34.91, \mathrm{M}_{\mathrm{EICMQ}}=36.84, \mathrm{M}_{\mathrm{EASSQ}}=18.91, \mathrm{M}$ total=30.22). 
Table 4: Combined Univariate ANOVA Table

\begin{tabular}{|l|c|c|c|c|c|c|c|}
\hline \multirow{3}{*}{ Source } & $\begin{array}{c}\text { Dependent } \\
\text { Variable }\end{array}$ & $\begin{array}{c}\text { Type III Sum } \\
\text { of Squares }\end{array}$ & df & Mean Square & F & Sig. & $\begin{array}{c}\text { Partial Eta } \\
\text { Squared }\end{array}$ \\
\hline \multirow{3}{*}{ Gender } & ESQA & 429.81 & 1 & 429.81 & 4.22 & .040 & .005 \\
\cline { 2 - 8 } & EICMQ & 552.34 & 1 & 552.34 & 4.60 & .032 & .005 \\
\cline { 2 - 8 } & EASSQ & 169.14 & 1 & 169.14 & 3.70 & .055 & .004 \\
\hline \multirow{3}{*}{ School year } & ESQA & 677.65 & 3 & 225.88 & 2.22 & .085 & .007 \\
\cline { 2 - 8 } & EICMQ & 1136.92 & 3 & 378.97 & 3.15 & .024 & .010 \\
\cline { 2 - 8 } & EASSQ & 471.73 & 3 & 157.24 & 3.43 & .017 & .011 \\
\hline \multirow{3}{*}{ Gender* } & ESQA & 323.93 & 3 & 107.98 & 1.06 & .365 & .003 \\
\hline \multirow{3}{*}{ Echool year } & EICMQ & 238.80 & 3 & 79.60 & .66 & .575 & .002 \\
\cline { 2 - 8 } & EASSQ & 111.42 & 3 & 37.14 & .81 & .489 & .003 \\
\hline \multirow{3}{*}{ Total } & ESQA & 92330.18 & 906 & 101.91 & & & \\
\cline { 2 - 8 } & EICMQ & 108817.61 & 906 & 120.11 & & & \\
\cline { 2 - 8 } & EASSQ & 41599.66 & 906 & 45.92 & & & \\
\cline { 2 - 8 } & ESQA & 1151745.00 & 914 & & & & \\
\cline { 2 - 8 } & EICMQ & 1306911.00 & 914 & & & & \\
\cline { 2 - 8 } & EASSQ & 350973.00 & 914 & & & & \\
\hline
\end{tabular}

a. $\mathrm{R}$ Squared $=.018$ (Adjusted R Squared $=.010)$

b. R Squared $=.021$ (Adjusted R Squared $=.014)$

c. $\mathrm{R}$ Squared $=.021$ (Adjusted R Squared $=.014$ )

This research found that there was no significant difference between gender and also no significant interaction between gender and grade groups of students when they are compared simultaneously on the ESQA, EICMQ, and EASSQ. However, this research revealed significant effects of grade on the ESQA, EICMQ, EASSQ, and total scores among the Freshman, Sophomore, Junior, and Senior. Though calculated effect sizes were small to large in magnitude (.03, .07, and .08 , respectively), the practical importance of the results is noted as the perspectives of university students in understanding their characteristics and E-learning and regulating their learning accordingly. From the records of this study, it could be observed that males were found to have a higher population than females on the assessment of E-learning system quality scores. Similarly, the number of males on the scores of E-learning instructor and course materials quality and E-learning administrative and support service quality was higher than that of females. In contrast, the E-learning service quality attribute (ESQA) in females is higher than males. This research reported that University students' perception of E-learning in teacher education University was medium. The main findings indicated that the distinction existed noticeably among groups of students with different studying experiences and educational backgrounds, compared to the students' learning of the E-learning System quality Scale. These findings showed a relationship between the school years of studying experience and the Undergraduates' assessed difficulties in implementing E-learning System quality in the University. We also found that there was a significant difference between male and female groups of University students when they are compared simultaneously on the ESQS subscales. This study's findings are comparable to Liaw \& Huang (2011) is supported by our findings that male students had a more optimistic E-learning mindset than female students did.

Additionally, seniors were found higher than those of the Freshman, Sophomore, and Junior on the E-learning system quality scores. The results of this experiment are quite different from the opposite of the previous results of González-Gómez et al. (2012), they showed that female students were more pleased with the subjects of E-learning than male students. According to Hung et al. (2010) they showed that gender did not reveal any statistical variations in the five Online Learning Readiness Scale dimensions including self-directed learning, online communication self-efficacy, motivation for learning, and learner control, junior and senior students demonstrated substantially higher preparation in the dimensions than freshman and sophomore students. 
Several limitations can be found in this study. The most visible limit is related to the samples that are only the students from two universities in Ho Chi Minh, Vietnam. As such, this is only a general assessment based on results obtained from students in Ho Chi Minh City. Another shortcoming is applying a questionnaire to collect data and selfreported measurements since each method can bring up different results. Future studies should address these constraints in order to make more precise evaluations. Overall, the results of this research are essential to lead to the assessment of students' perception of E-learning. With the desire to bridge the gap between research and practice, the study is carried out as a catalyst to expand parallel investigations among undergraduates in Vietnam, which gives us an overview of their perception and assists in promoting the application of E-learning in training programs at universities.

\section{CONCLUSIONS}

Evidence of current research on undergraduates' perception of the E-learning. The present work investigated the E-learning perception of Vietnamese undergraduates in Ho Chi Minh, Vietnam. It shows that university students' awareness of Elearning students is on average. It is the first research to investigate the understanding of E-learning by Teacher Education University students in Ho Chi Minh City, Vietnam, to the best of authors' knowledge. All findings from this study are necessary to improve the quality of E-learning systems for Teacher Education in Ho Chi Minh, Vietnam. Besides the little study done in Vietnam, Vietnamese lecturers need to understand their tasks better, to improve the quality of E-learning teaching in the current context.

\section{REFERENCES}

1. Amado-Salvatierra, H. R., Hilera, J. R., Tortosa, S. O., Rizzardini, R. H., \& Piedra, N. (2016). Towards a Semantic Definition of a Framework to Implement Accessible e-Learning Projects. J. UCS, 22(7), 921 -942.

2. Azeiteiro, U. M., Bacelar-Nicolau, P., Caetano, F. J., \& Caeiro, S. (2015). Education for sustainable development through elearning in higher education: experiences from Portugal. Journal of Cleaner Production, 106, 308-319.

3. Borgman, C. L. (2010). Scholarship in the digital age: Information, infrastructure, and the Internet. Cambridge, Massachusetts, US: MIT press.

4. Bowling, A. (2014). Research Methods in Health: Investigating Health and Health Services. United Kingdom: McGraw-Hill Education.

5. Cohen, J. (2013). Statistical Power Analysis for the Behavioral Sciences [electronic resource]. Hoboken, New Jersey, US: Taylor and Francis.

6. Cole, M. T., Shelley, D. J., \& Swartz, L. B. (2014). Online instruction, e-learning, and student satisfaction: A three year study. The International Review of Research in Open and Distributed Learning, 15(6), 111-131.

7. Dillman, D. A. (2000). Mail and Internet surveys: The tailored design method. New York: John Wiley \& Sons.

8. Edwards, S., \& Bone, J. (2012). Integrating peer assisted learning and eLearning: Using innovative pedagogies to support learning and teaching in higher education settings. Australian Journal of Teacher Education, 37(5), 1-12.

9. Fagö-Olsen, H., Lynggaard, C. D., Aanas, K., Cayé-Thomasen, P., \& Andersen, S. A. W. (2020). Developing a national elearning course in otorhinolaryngology: the Danish experience. European Archives of Oto-Rhino-Laryngology, 277, 18291836.

10. Freeze, R. D., Alshare, K. A., Lane, P. L., \& Wen, H. J. (2019). IS success model in e-learning context based on students' perceptions. Journal of Information Systems Education, 21(2), 173-182. 
11. Garavan, T. N., Carbery, R., O'Malley, G., \& O'Donnell, D. (2010). Understanding participation in e-learning in organizations: a large-scale empirical study of employees. International Journal of Training and Development, 14(3), 155168.

12. George, A. S. P. R. I. D. I. S., et al. "Assessment of e-Learning Methods in Public Administration. The Case of the Greek National School of Public Administration and Local Government."International Journal of Human Resource Management (2013).

13. González-Gómez, F., Guardiola, J., Rodríguez, Ó. M., \& Alonso, M. Á. M. (2012). Gender differences in e-learning satisfaction. Computers \& Education, 58(1), 283-290.

14. Grimm, L., \& Yarnold, P. (1995). Introduction to multivariate statistics Reading and Understanding Multivariate Statistics. Washington, D.C, USA: American Psychological Association.

15. Gupta, Manmohan, and Mala Sharma."A study on attitude of senior secondary school students towards E-Learning in relation to their gender, residential backward and nature." International Journal of Engineering, Science and Mathematics 7.1 (2018): 418-432.

16. Haines, K. (2016). Expanding the knowledge base of teachers' use of communication tools for language learning. System, 62, 102-112.

17. Harris, J., Felix, L., Miners, A., Murray, E., Michie, S., Ferguson, E., . . Edwards, P. (2011). Adaptive e-learning to improve dietary behaviour: a systematic review and cost-effectiveness analysis. Health Technology Assessment, 15(37), 1-160.

18. Hung, M.-L., Chou, C., Chen, C.-H., \& Own, Z.-Y. (2010). Learner readiness for online learning: Scale development and student perceptions. Computers \& Education, 55(3), 1080-1090.

19. Judy, M., Krishnakumar, U., \& Narayanan, A. H. (2012). Constructing a personalized e-learning system for students with autism based on soft semantic web technologies. Paper presented at the 2012 IEEE International Conference on Technology Enhanced Education (ICTEE).

20. Le, V.-Q., \& Tran-Chi, V.-L. (2019). Structural equation modelling analysis for internship satisfaction of Vietnam business students. International Journal of Education Economics and Development, 10(3), 258-275.

21. Leech, N. L., Barrett, K. C., \& Morgan, G. A. (2005). SPSS for intermediate statistics: Use and interpretation. New Jersey, USA: Psychology Press.

22. Liaw, S.-S., \& Huang, H.-M. (2011). A study of investigating learners attitudes toward e-learning. Paper presented at the 5th International Conference on Distance Learning and Education, Singapore.

23. Ludwig, B., Bister, D., Schott, T., Lisson, J., \& Hourfar, J. (2016). Assessment of two e-learning methods teaching undergraduate students cephalometry in orthodontics. European Journal of Dental Education, 20(1), 20-25.

24. Mayer, R. E., \& Moreno, R. E. (2010). Techniques that reduce extraneous cognitive load and manage intrinsic cognitive load during multimedia learning Cognitive Load Theory (pp. 131-152). Cambridge, UK: Cambridge University Press.

25. McKenzie, K., \& Murray, A. (2010). E-learning benefits nurse education and helps shape students' professional identity. Nursing Times, 106(5), 17-19.

26. Mishra, Richa, and KetanKotecha. "Teaching Communication Skills Student Engagement Through Blogging." International Journal of Humanities and Social Sciences (IJHSS) 2.2 (2012): 4.

27. Pallant, J. (2016). SPSS survival manual: a step by step guide to data analysis using IBM SPSS: Open University Press. 
28. Pham, L., Limbu, Y. B., Bui, T. K., Nguyen, H. T., \& Pham, H. T. (2019). Does e-learning service quality influence e-learning student satisfaction and loyalty? Evidence from Vietnam. International Journal of Educational Technology in Higher Education, 16(1), 1-26.

29. Tee, M. Y., \& Lee, S. S. (2011). From socialisation to internalisation: Cultivating technological pedagogical content knowledge through problem-based learning. Australasian Journal of Educational Technology, 27(1), 89-104.

30. Trukhacheva, N., Tchernysheva, S., \& Krjaklina, T. (2011). The impact of e-learning on medical education in Russia. Elearning and Digital Media, 8(1), 31-35.

31. Tsai, W.-H., \& Hsu, W. (2010). A novel hybrid model based on DEMATEL and ANP for selecting cost of quality model development. Total Quality Management, 21(4), 439-456.

32. Vanan, C. KURINCHI, and R. Subramani. "Digital divide: rural and urban college students 'attitude towards technology acceptance." International Journal of Communication and Media Studies (IJCMS) 5.4 (2015): 1-8.

33. Zakarneh, B. M. (2018). Effectiveness of E-learning Mode for Teaching English Language in Arab Universities. International Journal of Applied Linguistics and English Literature, 7(7), 171-181.

34. Zhang, D., \& Nunamaker, J. F. (2003). Powering e-learning in the new millennium: an overview of e-learning and enabling technology. Information Systems Frontiers, 5(2), 207-218. 